\title{
Non-classical 1 p36 deletion in a patient with Duane retraction syndrome: case report and literature review
}

\author{
Emiy Yokoyama ${ }^{1}$, Camilo E. Villarroel' ${ }^{1}$, Sinhué Diaz² ${ }^{2}$ Victoria Del Castillo ${ }^{1}$, Patricia Pérez-Vera ${ }^{3}$, Consuelo Salas ${ }^{3}$, \\ Samuel Gómez ${ }^{4}$, Reneé Barreda ${ }^{1}$, Bertha Molina ${ }^{5}$ and Sara Frias ${ }^{5,6^{*}}$ (1)
}

\begin{abstract}
Background: Monosomy of $1 \mathrm{p} 36$ is considered the most common terminal microdeletion syndrome. It is characterized by intellectual disability, growth retardation, seizures, congenital anomalies, and distinctive facial features that are absent when the deletion is proximal, beyond the 1 p36.32 region. In patients with proximal deletions, little is known about the associated phenotype, since only a few cases have been reported in the literature. Ocular manifestations in patients with classical 1 p36 monosomy are frequent and include strabismus, myopia, hypermetropia, and nystagmus. However, as of today only one patient with 1 p36 deletion and Duane retraction syndrome (DRS) has been reported.
\end{abstract}

Case presentation: We describe a patient with intellectual disability, facial dysmorphism, and bilateral Duane retraction syndrome (DRS) type 1. Array CGH showed a 7.2 Mb de novo deletion from 1p36.31 to 1p36.21.

Discussion: Our patient displayed DRS, which is not part of the classical phenotype and is not a common clinical feature in 1 p36 deletion syndrome; we hypothesized that this could be associated with the overlapping deletion between the distal and proximal 1 p36 regions. DRS is one of the Congenital Cranial Dysinnervation Disorders, and a genetic basis for the syndrome has been extensively reported. The HES3 gene is located at 1 p36.31 and could be associated with oculomotor alterations, including DRS, since this gene is involved in the development of the 3rd cranial nerve and the 6th cranial nerve's nucleus. We propose that oculomotor anomalies, including DRS, could be related to proximal 1 p36 deletion, warranting a detailed ophthalmologic evaluation of these patients.

Keywords: $1 \mathrm{p} 36$ deletion, HES3 gene haploinsufficiency, Duane retraction syndrome

\section{Background}

1p36 monosomy is the most common terminal microdeletion syndrome, with an incidence of 1 in every 5000 to 10,000 newborns and is found in more than $1.2 \%$ of patients with idiopathic intellectual disability [1]. Although the diagnosis may be suspected clinically, it is often confirmed after the application of molecular

\footnotetext{
${ }^{*}$ Correspondence: sarafrias@biomedicas.unam.mx

${ }^{6}$ Instituto de Investigaciones Biomédicas, Universidad Nacional

Autónoma de México, Avenida IMAN No. 1, Torre de Investigación, Insurgentes Cuicuilco, Coyoacán, 04530 Mexico City, Mexico

Full list of author information is available at the end of the article
}

cytogenetic tests. Most cases are de novo with a microdeletion size of approximately $5 \mathrm{Mb}$, ranging from 1.5 to $10.5 \mathrm{Mb}[2,3]$. The classical phenotype is associated with distal deletion of the most terminal chromosomal band (1p36.3) and includes intellectual disability, growth retardation, microcephaly, a distinctive craniofacial dysmorphism, and other variable congenital malformations. Larger deletions extending up to $1 \mathrm{p} 36.31$ show a severe neurological phenotype including profound disability, epilepsy, and deafness [3]. By comparison, proximal deletions beyond $1 \mathrm{p} 36.23$ (usually interstitial) show non-classical features including severe intellectual disability, hirsutism, abnormal ears, coarse facies, congenital original author(s) and the source, provide a link to the Creative Commons licence, and indicate if changes were made. The images or other third party material in this article are included in the article's Creative Commons licence, unless indicated otherwise in a credit line to the material. If material is not included in the article's Creative Commons licence and your intended use is not permitted by statutory regulation or exceeds the permitted use, you will need to obtain permission directly from the copyright holder. To view a copy of this licence, visit http://creativecommons.org/licenses/by/4.0/. The Creative Commons Public Domain Dedication waiver (http://creativeco mmons.org/publicdomain/zero/1.0/) applies to the data made available in this article, unless otherwise stated in a credit line to the data. 
heart disease, and variable cardiomyopathy $[4,5]$. These proximal deletions are more infrequent than the distal deletions, so knowledge about their associated phenotype (sometimes referred as "proximal 1p36 deletion syndrome") is limited [4]. The common ocular manifestations or functional visual problems described in both distal and proximal deletions are strabismus (30-35\%), myopia (17\%), hypermetropia (67\%), and nystagmus $(13 \%)[1,2]$. The presence of Duane retraction syndrome (DRS) has only been reported on one occasion, by Neal in 2006 [6].

DRS is a congenital eye movement disorder characterized by the variable limitation of abduction and globe retraction with narrowing of the palpebral fissure on abduction [7]. Although most cases are sporadic, sometimes this disorder is part of a recognizable genetic entity, whether as a main feature or as a rare associated finding [7]. DRS has also been associated with several cytogenetic anomalies, such as deletions on chromosomes 4 and 8 or the presence of an extra marker chromosome derived from chromosome 22 [8]. Here, we describe a patient with a $1 \mathrm{p} 36.21 \mathrm{p} 36.31$ deletion with a non-classical phenotype by reason of the uncommon DRS type 1 clinical feature. We also analyze the genes that might be implicated in the phenotype, and we propose that oculomotor anomalies including DRS, could be related to proximal $1 \mathrm{p} 36$ deletion.

\section{Case presentation}

The patient is a 13 years-old boy, the first child of healthy and non-consanguineous parents. He was born after an uneventful pregnancy; his birth weight was $3075 \mathrm{~g}$ (>10th percentile), and his length was $52 \mathrm{~cm}$ (75th percentile). At 6 months of age, the patient showed significant developmental delay and hypotonia. He was evaluated by the Genetics Department when he was 2 years old and he was able to speak, follow simple orders, identify colors, and count from 1 to 5 ; at 5 years old he had bladder and bowel control, however, he continued to display developmental delay, and currently goes to a special school, only speaks 10 words, and only counts to 10 . On physical examination, he showed weight, height, and cranial circumference below the 3rd percentile; coarse facies; narrow forehead; telecanthus; epicanthus; convergent strabismus; synophrys; hirsutism; a broad nasal bridge; large ears; teletelia; diastasis recti; retractile testes; and hands with brachydactyly and aberrant palmar creases (Fig. 1a-d). His ophthalmologic exam found limitations to abduction (right eye -4 ; left eye -3 ) with palpebral retraction and shots, as well as hypermetropia of the right eye, concluding the diagnosis of bilateral DRS type 1 . The prognosis of the patient is favorable, even until today he has had good evolution. His condition has not required any type of surgical intervention or specific treatment and consequently, he has not presented adverse events, anticipated events, or therapeutic changes.

G-banded karyotype, echocardiogram, and cerebral computed axial tomography scans did not reveal any alteration; aCGH showed an interstitial deletion of $7.2 \mathrm{Mb}$ with breakpoints at bands 1p36.31p36.21 $(5,414,227-12,632,782$; Fig. 1e). We confirmed this result using FISH analysis (Fig. 1f). The patient's karyotype was 46,XY.ish del(1)(p36.31p36.21)(RPL22-).arr[GRCh37/ hg19] 1p36.31p36.21(5414227_12632782)x1 dn. (ISCN 2016) [9]. The deletion encompassed more than 80 genes (USCS genome browser, GRCh37/hg19; Fig. 2). Both parents had normal karyotype, aCGH, and FISH analyses (Data not shown).

\section{Discussion}

Although 1p36 deletion syndrome is clinically recognizable, there is significant phenotypic variation among affected individuals $[10,11]$. This variation could be due to its genetic heterogeneity, which includes terminal and interstitial deletions of different lengths located throughout the 1p36 region; Wu et al. [12] proposed that most genes contributing to the phenotypic features of 1 p36 deletion syndrome were located distal to marker D1S2870 in 1p36.31 (chr1: 6,289,764-6,289,973), and subsequently this region was referred as the distal or classical region. Later, a further detailed analysis of this distal region was published by Shimada et al., defining a narrow critical region located at 1.8 to $2.2 \mathrm{Mb}$ for the classical phenotype, and another region at 5.4 to $6.2 \mathrm{Mb}$ associated with a more severe intellectual disability [13]. On the other hand, Kang et al. [5] identified interstitial deletions affecting 1p36.23-1p36.11 in five individuals using aCGH, concluding that the features seen in these children might constitute a distinct proximal 1p36 deletion syndrome located at 1p36.2 (chr1: 8,395,179-11,362,893; Fig. 2). Our patient's deletion overlaps distal and proximal regions, but not the narrow critical region for the classical phenotype (Fig. 2).

Clinically, our patient shared the developmental delay, generalized hypotonia, and cryptorchidism with the classical phenotype, but did not share the typical facial dysmorphism; he also shared the coarse facies, hirsutism, and the marked intellectual disability with the proximal phenotype. In addition, he displayed DRS, a congenital eye movement disorder characterized by a limited horizontal gaze and retraction of the globe into the orbit on attempted abduction, resulting in secondary narrowing of the palpebral fissure [14-16].

In 1974, Huber described three types of DRS. Type 1 is characterized by the marked limitation of abduction with normal or minimally defective adduction, while type 2 

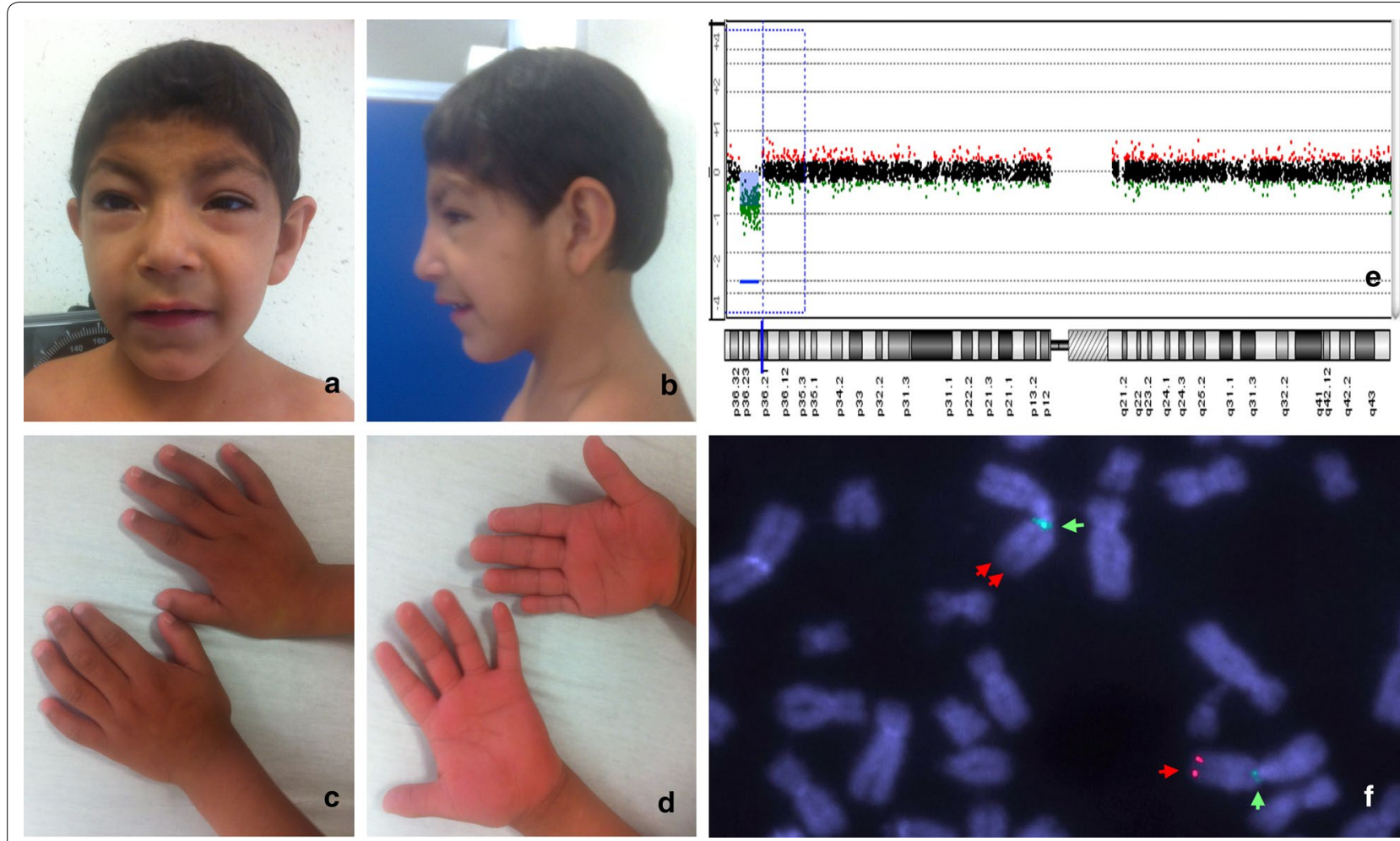

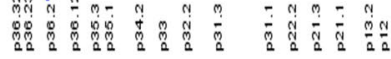

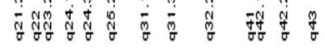

Fig. 1 a-d Patient with coarse facies, narrow forehead, telecanthus, epicanthus, convergent strabismus, synophrys, hirsutism, broad nasal bridge, large ears, brachydactyly, and aberrant palmar creases; e aCGH showing an interstitial deletion of $7.2 \mathrm{Mb}$ with breakpoints in bands 1 p36.31 p36.21: arr[GRCh37/hg19] 1p36.31p36.21(5414227_12632782)x1 dn; f DAPI counterstain FISH for the 1 p36 region on metaphase chromosomes: locus specific probe for 1 p36 marked with red fluorochrome (SureFISH, Agilent technologies, Santa Clara, USA) (one red arrow) and alpha satellite probe for chromosome 1 (chr1 CEP probe) marked with green fluorochrome (SureFISH, Agilent technologies, Santa Clara, USA) (one green arrow); deleted chromosome 1 with only one green fluorescent signal (one green arrow) and missing the red signal (two red arrows). Analysis was performed using an AXIO ImagerMI (Zeiss, Germany) microscope, and the images were obtained and analyzed using ISIS software (Meta Systems, Germany)

has normal or minimally defective abduction but marked limitation of adduction, and type 3 is characterized by the marked limitation of both abduction and adduction [7, 8, 17, 18]. In 2005, Kim and Hwang analyzed whether the presence of the abducens nerve changed depending upon the type of DRS, and found that the abducens nerve on the affected side was absent in all patients with type 1 DRS and in some type 3 DRS, but present in all patients with DRS type 2 [19].

Isolated DRS is usually sporadic, and less than $10 \%$ of cases show a familial pattern with autosomal dominant inheritance $[7,8,16]$. Some families with incomplete penetrance (the disease skips a generation) and variable expressivity (ranges in severity) have been documented [8]. DRS has a prevalence of about $1 / 1,000$ in the general population, with no particular race or ethnic group showing a predisposition but shows up to $60 \%$ predominance among females $[7,8]$. Prior reviews of DRS reported that this condition represents a $1-4 \%$ proportion of all strabismus cases, and that it is mostly unilateral and leftsided [8]. Electromyographic and MRI studies of patients with isolated DRS, revealed the absence of the abducens nerve and nuclei (6th cranial nerve) from the brainstem, and lateral rectus muscles partially innervated by the branches from the oculomotor nerves (3th cranial nerve) $[8,15,20]$. In accordance, it is currently accepted that DRS derives from developmental errors in the innervation of the ocular and facial muscles and it is included as one of the Congenital Cranial Dysinnervation Disorders [21-23].

\section{Association between $1 \mathrm{p} 36$ microdeletion and DRS}

Large series, such as those of Battaglia et al. [1] or Shapira et al. [10], have reported ocular manifestations in $52-75 \%$ of patients with $1 \mathrm{p} 36$ microdeletion, including strabismus in $30-35 \%$ [1, 2], but none of them mentioned DRS; in fact, none of the genes responsible for the clinical manifestations of classical 1p36 microdeletion have been associated with DRS (Table 1) [13, 24, 25].

Neal et al. reported a patient with 1 p36 microdeletion and periventricular nodular heterotopia who also displayed DRS [6]. The patient had a terminal deletion of 


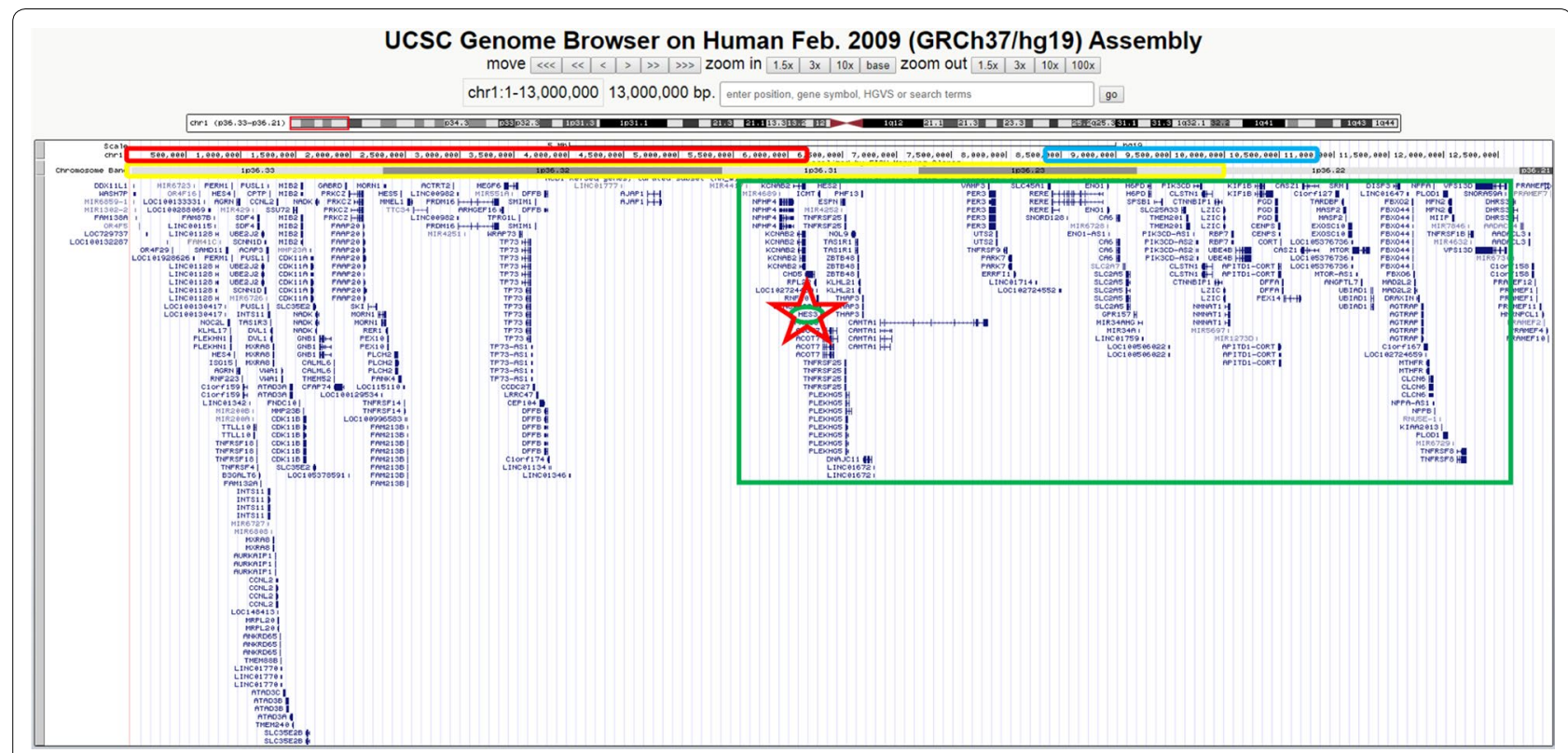

Fig. 2 The USCS genome browser (GRCh37/hg19) showed more than 80 genes involved in the deleted region in our patient (green rectangle) which overlaps with both the proximal region (red rectangle) and the distal region (blue rectangle). Also, we showed that the HES3 gene (red star) is included in both our patient's deleted region (green rectangle) and Neal's deleted region (yellow rectangle)

9.6 $\mathrm{Mb}$, sharing with our patient the $1 \mathrm{p} 36.22$ region; the authors did not propose any candidate gene for DRS. In a detailed review of all the genes located in the overlapped region of Neal's patient and our patient (Fig. 2), we found that the HES3 gene could correlate with the pathophysiology of DRS, since this gene has been associated with the morphogenesis of the midbrain-hindbrain boundary and anterior hindbrain, and the development of the oculomotor nerve (3rd cranial nerve) [26-30].

HES family genes are the mammalian homologues of the Hairy and Enhancer Split genes in Drosophila, required for normal neurogenesis; they encode basic helix-loop-helix (HLH) transcriptional repressors [2830]. In human, there are seven members in the HES family, HES1-7, which regulate developmental pathways in several tissues, including brain morphogenesis [29]. The developing nervous system is divided into many compartments by boundary structures; several knockout mice studies demonstrated that Hes genes are crucial to maintaining these boundary structures in the developing brain $[27,28]$. The embryonic hindbrain is divisible into eight rhombomeres (Rh) [31], the abducens motor nucleus is included in Rh6 which is visible at stage 16 of human embryo development (before 6-week), when all the neuromeres have appeared [32, 33]. In this way, the haploinsufficiency of the HES3 gene could be related to the altered ocular mobility, specifically DRS in our patient, by affecting the nerves and nuclei of both the 3rd cranial nerve derived from the midbrain close to the hindbrain junction and the 6th cranial nerve derived partially from Rh6.

We looked for other previously reported patients who had 1 p36 deletions that included the HES3 gene and compared them with our patient (Table 2). In addition to Neal's patient [6], Shimada et al. analyzed 50 patients with different levels of 1 p36 deletion, 18 of which presented loss of the HES3-containing region (Fig. 2), yet only one (patient 46) was reported to have an oculomotor disturbance; however, among the 17 remaining patients, four had strabismus [24]. It could be possible that some of the cases reported as strabismus may in fact be DRS, although the globe retraction and the narrowing of the eyelid fissure are visible data on physical examination, but if the extraocular motility test was not performed, DRS might not have been detected. Even so, only a part of the patients with HES3 deletion present eye disorders; the absence of DRS in these patients may be related with incomplete penetrance and variable expressivity, already observed in the familial type of DRS [34-36]. It is then necessary to study other patients with $\operatorname{del}(1 \mathrm{p} 36)$ with haploinsufficiency of HES3, to explore its role in the presence of DRS type 1.

Furthermore, non-syndromic DRS can be due to mutations in genes other than HES3, DRS1 in 8q13-OMIM\#126800; DRS2 (CHN1 gene in 2q31.1) - OMIM\#118423; DRS3 (MAFB gene in 20q12) OMIM\#608968, which have an autosomal dominant inheritance. Although no other cases of DRS were found 


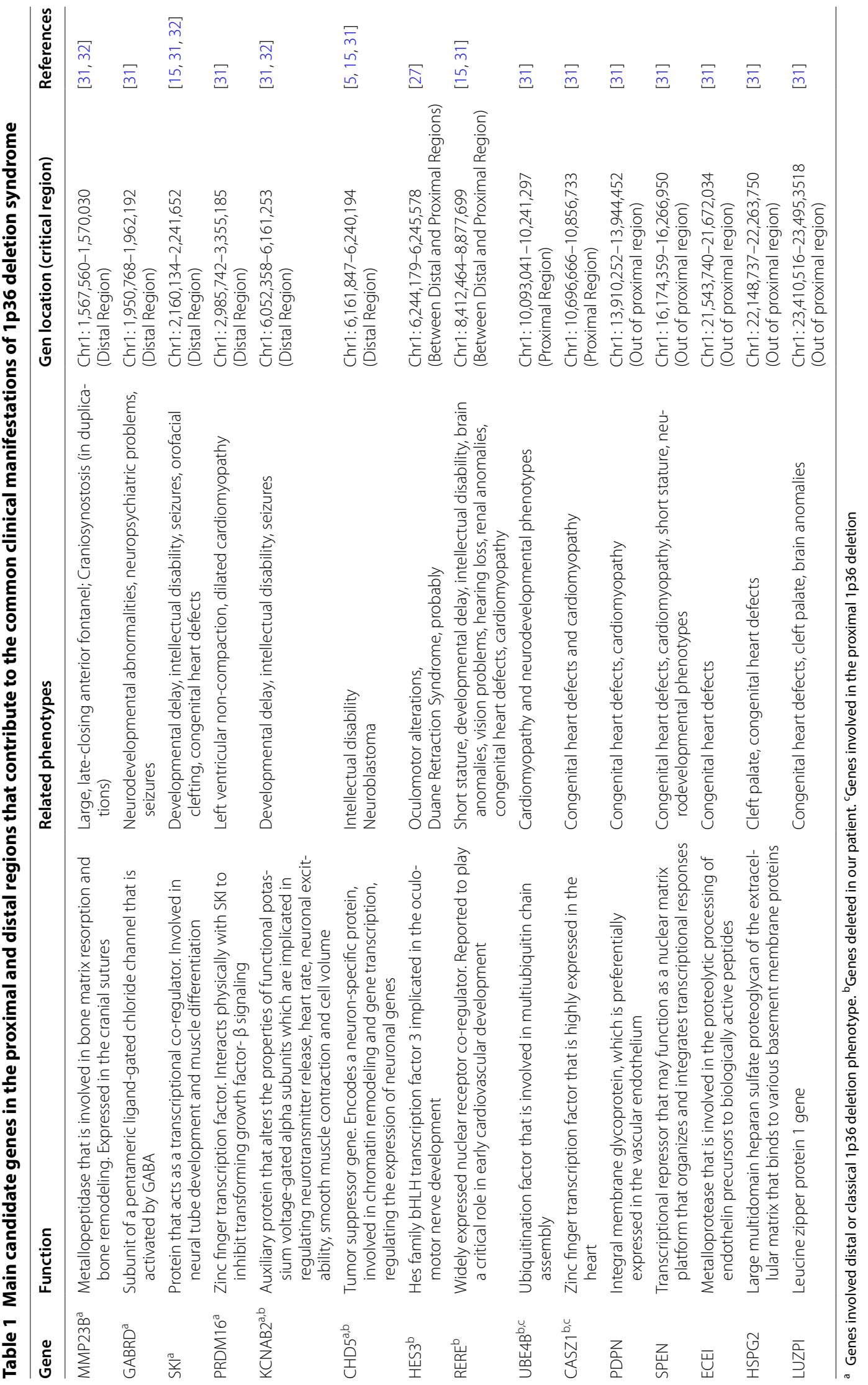


Table 2 Description of deleted genomic regions of patients with 1 p36 monosomy and Duane retraction syndrome

\begin{tabular}{|c|c|c|c|c|}
\hline Patients & Chromosomal Region & Initial nucleotide & Final nucleotide & DRS \\
\hline Present patient & $1 p 36.31 p 36.21$ & $5,414,227$ & $12,632,782$ & Yes \\
\hline Neal et al. [6] & 1 pter-p36.22 & 1 & $9,600,000$ & Yes \\
\hline Shimada et al. [15] (Patient 46) & 1 pter-p36.22 & 1 & $10,001,011$ & Possible \\
\hline
\end{tabular}

HES3 gene located in chr1: 6,244,179-6,245,578

DRS Duane retraction syndrome

a Oculomotor disturbance; Distal critical region (classical) 1pter-p36.31=1-6,289,973 [13, 14]; Proximal critical region 1p36.23-p36.22 =8,395,179-11,362,893 [5, 14]

in the parents or other relatives of the present index case, and that does not support an additional mutation outside of $1 \mathrm{p} 36$, not having intentionally searched for these mutations is a limitation of the present study.

In conclusion, we propose that in non-classic $1 \mathrm{p} 36$ deletion syndrome, the HES3 gene could be associated with oculomotor alterations, including DRS. However, further studies and more patients that include a complete clinical history and physical examination, as well as molecular description, are needed to confirm this finding. Finally, because DRS could be mistaken for common strabismus if it is not intentionally sought, we recommend a detailed ophthalmologic evaluation in all patients with $1 \mathrm{p} 36$ deletion.

\section{Acknowledgements}

We would like to thank Federal Funds 2015/INP and CONACYT (CONACYTSALUD-87792) for their financial support. The aCGH was carried out at Laboratory GENETADI BIOTECH in Bilbao, Spain.

\section{Authors' contributions}

EY and SF contributed to the design and development of the protocol, analyzed the aCGH results, wrote the manuscript, and designed the figures. VC and $\mathrm{CV}$ contributed to the design of the protocol and clinical description and analyzed results. BM, PPV, and CS performed the G-banded karyotype analysis and FISH technique. SG and SD wrote the first draft of the manuscript and SD did the first draft of Table 1; both proposed the HES3 gene. RB analyzed the data and literature, contributed to the clinical description, and revised the manuscript for the English language. All authors read and approved the final manuscript.

\section{Funding}

This study was partially supported by CONACYT FOSSIS-

S0008-2008-C01-87792 and Instituto Nacional de Pediatría (México) Fondos Federales 2013, project 2009/06. The funding body did not participate in the design of the study; the collection, analysis, or interpretation of data; or in writing the manuscript. EY received a fellowship, CONACYT-176523 (Doctorado en Ciencias Médicas, Odontológicas y de la Salud, Universidad Nacional Autónoma de México)

\section{Availability of data and materials}

Routine ophthalmologic examination included best corrected visual acuity (BCVA), slit lamp examination, Goldmann applanation tonometry, gonioscopy, and dilated fundus examination. Genomic DNA from the patient and both parents was amplified and labeled using the CGH-Labeling Kit for Oligo Arrays (Enzo Life Sciences, USA), and was then applied to $60 \mathrm{k}$ oligonucleotide arrays according to the manufacturer's protocol (Agilent, Santa Clara, USA). The aCGH was performed using paired-samples, first pairing the patient and mother and then pairing the patient and father. Slides were scanned using a microarray scanner with Surescan High Resolution Technology (Agilent, Santa Clara, USA). Image quantification, array quality control, and aberration detection were performed using Agilent Feature Extraction and DNA Analytics software (Agilent, Santa Clara, USA) according to the manufacturer's instructions. The deletion was verified using SureFISH probes (Agilent). Changes identified in the samples were visualized using the UCSC Genome Browser website (http://genome.ucsc.edu) and compared to the Database of Genomic Variants (http://projects.tcag.ca/variation) to exclude benign variants. The DECIPHER (https://decipher.sanger.ac.uk/) and ECARUCA (http://umcecaruca01.exter n.umcn.nl:8080/ecaruca/ecaruca.jsp) databases were used as resources to aid in genotype-phenotype correlation.

\section{Ethics approval and consent to participate}

This study has been performed in accordance with the Declaration of Helsinki and was approved by the Ethics and Research committees of the National Institute of Pediatrics (Mexico; Project No. 06/2009). Written informed consent was obtained from the patient's parents for participating in this study.

\section{Consent for publication}

Written informed consent was obtained from the patient's parents for publication of this case report and accompanying images.

\section{Competing interests}

The authors declare that they have no competing interests.

\section{Author details}

${ }^{1}$ Departamento de Genética Humana, Instituto Nacional de Pediatría, Mexico City, Mexico. ${ }^{2}$ Enlace Científico, Shire Pharmaceuticals México, Mexico City, Mexico. ${ }^{3}$ Laboratorio de Genética y Cáncer, Departamento de Genética Humana, Instituto Nacional de Pediatría, Mexico City, Mexico. ${ }^{4}$ CRIT Chiapas, Tuxtla, Mexico. ${ }^{5}$ Laboratorio de Citogenética, Departamento de Genética Humana, Instituto Nacional de Pediatría, Mexico City, Mexico. ${ }^{6}$ Instituto de Investigaciones Biomédicas, Universidad Nacional Autónoma de México, Avenida IMAN No. 1, Torre de Investigación, Insurgentes Cuicuilco, Coyoacán, 04530 Mexico City, Mexico.

Received: 30 May 2020 Accepted: 19 August 2020

Published online: 07 September 2020

\section{References}

1. Battaglia A, Hoyme HE, Dallapiccola B, et al. Further delineation of deletion 1 p36 syndrome in 60 patients: a recognizable phenotype and common cause of developmental delay and mental retardation. Pediatrics. 2008:121:404-10

2. Heilstedt HA, Ballif BC, Howard LA, et al. Physical map of 1p36, placement of breakpoints in monosomy $1 \mathrm{p} 36$, and clinical characterization of the syndrome. Am J Hum Genet. 2003;72(5):1200-12.

3. Yu W, Ballif BC, Kashork CD, et al. Development of a comparative genomic hybridization microarray and demonstration of its utility with 25 wellcharacterized 1 p36 deletions. Hum Mol Genet. 2003;12(17):2145-52.

4. Rankin J, Allwood A, Canham N, et al. Distal monosomy 1p36: an atypical case with duodenal atresia and a small interstitial deletion. Clin Dysmorphol. 2009;18(4):222.

5. Kang SH, Scheffer A, Ou Z, et al. Identification of proximal 1 p36 deletions using array-CGH: a possible new syndrome. Clin Genet. 2007;72(4):329-38. 
6. Neal J, Apse K, Sahin M, et al. Deletion of chromosome 1 p36 is associated with periventricular nodular heterotopia. Am J Med Genet A. 2006;140A:1692-5.

7. Mohan K, Sharma A, Pandav SS. Differences in epidemiological and clinical characteristics between various types of Duane retraction syndrome in 331 patients. JAAPOS. 2008;12(6):576-80.

8. Yüksel D, Orban de Xivry JJ, Lefèvre P. Review of the major findings about Duane retraction syndrome (DRS) leading to an updated form of classification. Vis Res. 2010:50(23):2334-47.

9. McGowan-Jordan J, Simons A, Schimd M. ISCN: an international system for human Cytogenomic nomenclature. Basel: Karger; 2016.

10. Shapira SK, McCaskill C, Northrup H, et al. Chromosome 1 p36 deletions: the clinical phenotype and molecular characterization of a common newly delineated syndrome. Am J Hum Genet. 1997;61:642-50.

11. Gajecka M, Mackay KL, Shaffer LG. Monosomy 1 p36 deletion syndrome. Am J Med Genet C. 2007;145C:346-56.

12. Wu YQ, Heilstedt HA, Bedell JA, et al. Molecular refinement of the $1 \mathrm{p} 36$ deletion syndrome reveals size diversity and a preponderance of maternally derived deletions. Hum Mol Genet. 1999;8(2):313-21.

13. Shimada S, Shimojima K, Okamoto N, et al. Microarray analysis of 50 patients reveals the critical chromosomal regions responsible for 1 p36 deletion syndrome-related complications. Brain Dev. 2015;37(5):515-26.

14. Villarroel CE, Álvarez RM, Gómez-Laguna $L$, et al. First two Mexican cases of monosomy 1 p36: possible diagnosis in patients with mental retardation and dysmorphism. Arch Argent Pediatr. 2011;109(3):e55-8.

15. Hotchkiss MG, Miller NR, Clark AW, Green WG. Bilateral Duane's retraction syndrome: a clinicalpathological case report. Arch Ophthalmol. 1980;98:870-4.

16. Gutowski N. Duane's syndrome. Eur J Neurol. 2000;7:145-9.

17. Huber A. Electrophysiology of the retraction syndrome. Br J Ophthalmol. 1974:68:293-300

18. Yang HK, Kim JH, Hwang JM. Abducens nerve in patients with type 3 Duane's retraction syndrome. PLoS ONE. 2016;11(6):e0150670.

19. Kim JH, Hwang JM. Presence of the abducens nerve accord ing to the type of Duane's retraction syndrome. Ophthalmology. 2005;112(1):109-13.

20. Parsa CF, Grant E, Dillon WP Jr, et al. Absence of the abducens nerve in Duane syndrome verified by magnetic resonance imaging. Am J Ophthalmol. 1998;125:399-401.

21. https://rarediseases.org/rare-diseases/duane-syndrome/.

22. Gutowski NJ, Bosley TM, Engle EC. 110th ENMC International Workshop: the congenital cranial dysinnervation disorders (CCDDs): Naarden, The Netherlands, 25-27 October, 2002. Neuromuscul Disord. 2003;13:573-8.
23. Engle EC. Genetic basis of congenital strabismus. Arch Ophthalmol. 2007;125:189-95.

24. Jordan VK, Zaveri HP, Scott DA. 1 p36 deletion syndrome: an update. Appl Clin Genet. 2015;8:189-200.

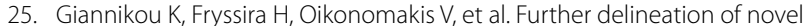
1 p36 rearrangements by array-CGH analysis: narrowing the breakpoints and clarifying the "extended" phenotype. Gene. 2012:506(2):360-8.

26. https://www.ncbi.nlm.nih.gov/gene/390992.

27. Hirata H, Tomita K, Bessho Y, Kageyama R. Hes 1 and Hes3 regulate maintenance of the isthmic organizer and development of the mid/hindbrain. EMBO J. 2001;20(16):4454-66.

28. Hatakeyama J, Bessho Y, Katoh K, et al. Hes genes regulate size, shape and histogenesis of the nervous system by control of the timing of neural stem cell differentiation. Development. 2004;131(22):5539-50.

29. Kobayashi T, Kageyama R. Expression dynamics and functions of Hes factors in development and diseases. Curr Top Dev Biol. 2014;110:263-83.

30. Lobe CG. Expression of the helix-loop-helix factor, Hes3, during embryo development suggests a role in early midbrain-hindbrain patterning. Mech Dev. 1997;62:227-37.

31. Bass AH, Baker R. Phenotypic specification of hindbrain rhombomeres and the origins of rhythmic circuits in vertebrates. Brain Behav Evol. 1997;50(Suppl 1):3-16.

32. Müller F, O'Rahilly R. The initial appearance of the cranial nerves and related neuronal migration in staged human embryos. Cells Tissues Organs. 2011;193(4):215-38.

33. Carlson BM. Early patterning and development of the central nervous system. reference module in biomedical sciences. Amsterdam: Elsevier; 2014. p. 1-11

34. https://www.ncbi.n/m.nih.gov/books/NBK1190.

35. Torres F, Barbosa M, Maciel P. Recurrent copy number variations as risk factors for neurodevelopmental disorders: critical overview and analysis of clinical implications. J Med Genet. 2016;53(2):73-90.

36. Harel T, Lupski JR. Genomic disorders 20 years on-mechanisms for clinical manifestations. Clin Genet. 2018;93(3):439-49.

\section{Publisher's note}

Springer Nature remains neutral with regard to jurisdictional claims in published maps and institutional affiliations.
Ready to submit your research? Choose BMC and benefit from:

- fast, convenient online submission

- thorough peer review by experienced researchers in your field

- rapid publication on acceptance

- support for research data, including large and complex data types

- gold Open Access which fosters wider collaboration and increased citations

- maximum visibility for your research: over 100M website views per year

At $\mathrm{BMC}$, research is always in progress.

Learn more biomedcentral.com/submissions 